\author{
И. А. Шаронов \\ Российский государственный гуманитарный Университет (РГГУ). \\ (Москва, Россия) \\ Igor_sharonov@mail.ru
}

\title{
ВОТ ВЕДЬ И НАДО ЖЕ! \\ ПУТЬ ОТ КОНСТРУКЦИИ КО ВТОРИЧНОМУ МЕЖДОМЕТИЮ
}

Статья посвящена выяснению происхождения вторичных междометий вот ведь и надо же. Данные междометия предположительно происходят из стандартных синтаксических конструкций, подвергшихся в дискурсе эллиптированию ряда компонентов, передающих конкретную коммуникативную ситуацию. Переход синтаксических конструкций во вторичные междометия происходит в два этапа. На первом этапе конструкции перестраиваются для более обобщенного описания и начинают использоваться в дискурсе в качестве метатекстовых единиц для подготовки собеседника к восприятию необычной информации. Стереотипное использование в данной позиции приводит конструкции к потере нескольких компонентов и их идиоматизации, то есть превращает их в коммуникативные формулы. Данные формулы служат для введения необычной информации и передают отношение к ней говорящего лица. На втором этапе коммуникативные формулы используются в диалоге как реакции субъекта на полученную информацию. В этой позиции конструкция теряет еще некоторые компоненты и служит только для выражения удивления субъекта на воспринятую информацию, то есть превращается из коммуникативной формулы во вторичное междометие.

Ключевые слова: грамматикализация, дискурс, диалог, метатекст, эллипсис, десемантизация, вторичные междометия.

Самостоятельные реплики Вот ведь и Надо же используются в речи как звуковые эмоциональные симптомы неподготовленности человека к воспринимаемой в данный момент информации. Они относятся ко вторичным междометиям со значением удивления. Иорданская дает следующее толкование глагола удивитьcя: А удивляется В = 'А испытывает «возбужденное» эмоциональное состояние', А или уверен в осуществлении события В или считает, что осуществление В высоковероятно, до $\mathrm{t}_{0}$ А считал, что осуществление события В маловероятно' [Иорданская 1970, с. 24]. Этологи относят удивление к базовым и универсальным эмоциям, 
поскольку симптоматика удивления имеет характерные мимические признаки, отмечаемые во всех исследованных культурах: приоткрытый рот, округленные глаза, приподнятые брови и т.д. [Бутовская 2004]. Такое паралингвистическое сопровождение при самостоятельных репликах Вот ведь и Надо же вполне обычно.

Непроизвольная эмоциональная реакция удивления выражается главным образом вокальными жестами, неязыковыми звуками: O-о!, Oй!, Ба!, Bay!, которые в лингвистике относят к первичным междометиям. Вторичные же междометия построены с помощью стандартных единиц языка при грамматической аморфности и десемантизированности всей конструкции. Кроме двух названных междометий удивление может быть передано целым рядом других вторичных единиц: О Боже, Батюшки, Вот так так, Вот это да, Вот те и на, Вот черт, Блин и т. п. Все эти языковые единицы, будучи вторичными, являют собой переход от стандартных языковых употреблений слов и конструкций в междометные. Источники и пути перехода во вторичные междометия не всегда очевидны. Их анализ может позволить уточнить особенности употребления и выбора говорящим той или иной единицы при выражении удивления.

Согласно теории грамматикализации [Lehmann 2004] между высказываниями, имеющими общие компоненты, можно выстроить систему связей с наследованием признаков, представить высказывания как некоторую последовательность формальных и семантических модификаций, идущих от «источника», то есть от наиболее полной и неидеоматизированной формы или конструкции к более идиоматичным и грамматикализованным. Вторичные междометия - это результат грамматикализации языковых форм и конструкций, в процессе которой они получают новый грамматический статус. Грамматикализация переводит семантику языковых форм на более абстрактный уровень [Traugott 1995], позволяя им, в частности, передавать сообщения об эмоциях говорящего лица. Модификации происходят в дискурсивных контекстах — монологических и диалогических, где конструкции способны приобретать прагматические свойства и подвергаться опрощению, сближаясь либо с дискурсивными маркерами (вводными словами, коннекторами, релятивами), либо с грамматически аморфными реактивными репликами (коммуникативами, вторичными междометиями). В последнее времени исследователи, занимающиеся междометиями, все чаще начинают интересоваться путями перехода словоформы в междометие. Например, в работе [Gehweiler's 2008] проводится анализ междометия 'gee!' этимологически связанный с 'Jesus'. В работе [Cruz 2017] описываются переход некоторых групп знаменательных слов во вторичные междометия, главным образом за счет расширения их значения. Однако кроме вторичных междометий, построенных на одиночных словоформах, существует большой класс грамматических идиом - вторичных междометий и коммуникативов, построенных на основе сочетаний служебных слов. Такого рода единицы ведут свое происхождение из свободных конструкций и фразеосхем (см. [Шаронов 2008; 2009]).

Настоящая статья посвящена попытке построения последовательности трансформаций, которую претерпевает синтаксически свободная «конструкция-источ- 
ник» по пути к вторичному междометию. Переход синтаксических конструкций во вторичные междометия происходит в два этапа. На первом этапе конструкции перестраиваются для более обобщенного описания и начинают использоваться в дискурсе в качестве метатекстовых единиц для подготовки собеседника к восприятию необычной информации. Стереотипное использование в данной позиции приводит конструкции к потере нескольких компонентов и их идиоматизации, то есть превращает их в коммуникативные формулы. Данные формулы служат для введения необычной информации и передают отношение к ней говорящего лица. На втором этапе коммуникативные формулы используются в диалоге как реакции субъекта на полученную информацию. В этой позиции конструкция теряет еще некоторые компоненты и служит только для выражения удивления субъекта на воспринятую информацию, то есть превращается из коммуникативной формулы во вторичное междометие. В качестве примера описания этапов трансформации и его результата рассматриваются междометия Вот ведь (как)! и Надо же!

\section{Вот ведь (как)}

Гипотетическим источником, обратным концом цепочки модификаций к вторичному междометию Bom ведь (как) является стандартная финитная конструкция: Они ходят / здороваются / сnят. Добавление в такие предложения частиц вот как привносит указание (вот) на способ совершения действия (как): Вот как они ходят / здороваются / спят и т. д. Идиоматизированное сочетание частиц вот ведь как с фразовым ударением на частицу вот и обобщающим глаголом бывает приводит к формированию модализованной дискурсивной единицы вот ведь как бывает (в жизни). Данный дискурсив используется говорящим / пишущим лицом, чтобы ввести или завершить им сообщение о необычном или странном событии, поделиться своим удивлением перед непредсказуемостью жизни. Ср.:

Язычник и огнепоклонник стал набожным православным; мефистофелеподобный анархист и панк склоняется к тоталитаризму; внук антифашиста пишет совершенно наџистские песни. Вот ведь как бывает в жизни, э? (М. Свирепьй. Байда: музыка).

Удачно получилось у меня с тёщей, как говорят - осенило. Потом я её даже полюбил, и она меня, хотя ругались по-прежнему. Умерла она года через два, - я о ней очень жалел, вот ведь как бывает (И. Грекова. Хозяева жизни).

Вот ведь как бывает, оказывается. ЛЮ и Роман Якобсон знали друг друга с далекого детства, дружили еще их матери. (В. Катанян. Прикосновение кидолам).

Данной дискурсивной единице близка аналогичная конструкция с глаголом noлучается, которая в социальных контекстах часто получает негативную коннотацию, связанную с идеей о несправедливости жизни («комплекс Сальери»). 
Вот ведь как получается - люди трудятся, в результате их работы меняется мир. Но чем больше они старались, тем меньше в старости такого дела, к которому они привыкли, которое умели. (С. Гансовский. Млечнылй nymb).

- Ну, голубчик, рассказывай: где, как, когда, почему и откуда? - Родион Иванович дотронулся до локтя Гурова и легонько подтолкнул его к выходу из зала. - Вот ведь как получается... Раньше в отряде я бы вас так спросил. А нынче вы командуете (Г. Семар. Снежка - речка чистая).

Регулярность использования в речи обеих дискурсивных конструкций приводит под воздействием принципа экономии усилий к эллипсису глаголов без изменения дискурсивных характеристик этих конструкций.

\section{Вот ведь как бывает/получается; Вот ведь как!}

Переводил я очень хорошо, это быстро поняли, - и в итоге образовалась почему-то целая очередь поэтов, <..> жаждущих, чтобы книги их перевел именно я, только я, непременно - я, и никто другой, вот ведв как (В. Д. Алейников. Тадзимас).

Геройское участие в защчите Отечества не считалось стоящим внимания доводом против обвинения в безродном космополитизме. Вот ведв как! (К. Ваншенкин. Писательский клуб).

Дополнительная потеря частицы как также не приводит к изменению семантики конструкции, хотя появляется тенденция к дискурсивному ограничению: Bom ведь имеет тенденцию к использованию только в инициальной позиции.

- Я вас забинтую, - сказал Вадим Петрович. - Я этому обучился на сборах. Вот ведь! Считал дурьим делом, а могу вам помочь (Г. Щербакова. Актриса и милиционер).

Я к Веселому - он то же самое: «Не знаю никакого Тихона». Тогда разыскал самого себя. Но и я его не помнил. Вот ведь! В четверг Тихона помню, а во вторник-нет. (Е. Прочкин. Механика вечности).

Сопоставление вариантов конструкции позволяет подтвердить тенденцию, отмеченную в свое время Ш. Балли. Автор «Французской стилистики» пишет об обратно пропорциональных отношениях между эмоциональной составляющей и полнотой выражения мысли в предложении. В качестве иллюстрации исследователь приводит ряд возможных высказываний человека при неожиданной встрече - от максимально полного высказывания: «Я удивлен тем, что встретил вас здесь» до междометного выкрика «O!» [Балли 2011: 51]. В рассматриваемом нами случае потеря компонентов конструкции, не приводя к семантическим сдвигам, также усиливает эмоциональную составляющую: удивление, недопонимание говорящим возможности того, о чем он рассказывает. Ср.: 
Вот ведь как бывает в жизни;

Вот ведь как бывает;

Вот ведь как;

Bom ведb.

В диалогической речи, в реагирующих реакциях говорящего на сообщение собеседника два наиболее кратких варианта конструкции: Bom ведь как и Вот ведь претерпевают окончательную трансформацию. Они переходят из ранга дискурсива, метатекстовой единицы, передающей отношение говорящего к своему сообщению, в ранг самостоятельной реплики. Конструкция передает удивление, растерянность или легкую досаду, имеет регулярное жестово-мимическое сопровождение: говорящий может слегка склонить голову, покачать ей слева направо, присвистнуть. Происходит переход конструкции во вторичное междометие со значением удивления, растерянности как реакции на сообщения об имевшем место странном, чаще негативно оцениваемом событии.

Молодая женщина вдруг плачет - рассказывает, что недавно она сбилась с дороги и её изнасиловали. Вовка-стрелок, удивлённьй, присвистыввает: вот ведь как! Посочувствовав, он спрашивает (с любопьттством), сколько же их было? (В. Маканин. Кавказский пленный).

Мы с братом очень похожи, только я без усов. Он попросил меня подежурить, пока он свою девушку свозит к морю. Это сразу можно было бы заметить - на мне фуражка не в размер. - Вот ведь как, - сказал К. М., - а я подумал, это у вас голова в рост пошла. (И. Адамаикий. Утешитель).

- А мать его как зовут? Гурский широко раскрыл глаза: - Вот ведь! Из головы вон... Маша... Варя... (С.Д. Мстиславский. Грач - птица весенняя).

\section{Вторичное междометие Надо же!}

В словаре под редакцией В. В. Морковкина [ССРЯ 1998] есть статья Надо же: Надо же, надо ж, это же надо, это ж надо, междометие, разговорное.

1.0. Восклицание, которое употребляется для выражения удивления, изумления. Аня, надо же, успела- таки на поезд. Вы Леонид Павлович Мухин? - Надо же, узнали!

1.1. в составе сказуемого. Употребляется для выражения возмущения или досады. Зимой ходить без шапки - надо же такое придумать! Надо же мне было именно сегодня забыть записную книжку! Надо же так испачкаться!.

Источником для формирования вторичного междометия предположительно являются конструкции: 'Х-у надо + инфинитив' и 'Надо, чтобы Р'. Центральный компонент конструкции, на который падает фразовое ударение - модальное слово надо, связанное с социальной необходимостью и целеполаганием. Природе, как кажется, ничего не надо, надо человеку, обществу. Под $X$-ом подразумевается лицо, одушевленный субъект. 
В настоящем времени конструкция описывает нефактивную пропозицию: $\mathrm{Hu}$ колаю надо войти; Начальству надо, чтобы мы сдали работу в срок. В прошедшем времени конструкция может передавать фактивное значение описываемого действия в полемическом контексте, мотивирующем совершение действия. Добавление частицы же усиливает мотивацию, акцентируя внимание на надо в качестве носителя фразового ударения:

В Париже принудительный выбор был куда уже, да и материальные возможности дающего стали уже не те. Однако надо же было кому-нибудь давать и здесь (Д. Маркиш. Стать Лютовым. Вольные фантазии из жизни писателя Исаака Бабеля).

Эти жалобы звучали довольно глупо в письме исключенного гимназиста. $<\ldots>$ Ведь я и месяца еще не прослужил на позициях. Надо же было мне свалить на кого-то свою неприспособленность к новым условиям жизни и вечное ощущение беспричинной грусти (В. П. Катаев. Юношеский роман).

Конструкция 'Х-у же надо было + инфинитив' имеет субъективно-модальную модификацию с фиксированным порядком слов: '(И / Ну) Надо же было Х-у + инфинитив'. Агент действия, намеренного или ненамеренного, в модализованной конструкции может быть как одушевленным, так и неодушевленным. Целеполагание, передаваемое словом надо метафорически приписывается судьбе, игре случая. Конструкция выражает удивление, а в ряде примеров досаду говорящего по поводу описываемого им события.

Жизнь иногда устраивает также пируэты... Надо же было Никите Михалкову, подбирая музыку к титрам в фильме «Пять вечеров», напасть в архивах радио именно на эти «Бульвары» (Л. Гурченко. Аплодисменты)

Блин, надо же было этому розовому свечению так нам подгадить! (Д. Емец. Таня Гроттер и колодец Посейдона).

Конструкция используется в монологическом дискурсе при описании никак не контролируемых совпадений, странных случайностей, вторгающихся в судьбу человека. При замене инфинитива с дательным субъекта обобщенным оборотом со значением события такому случиться: '(И) Надо же было такому случиться!' происходит дискурсивная модификация конструкции, переход ее в интродуктивную формулу описании действия, приводящего или связанного с непредвиденной ситуацией, в которую попал герой повествования.

И надо же было такому случиться, что, когда он нажимал на кнопку звонка, появилась Нина Софьина. (А. Слаповский. Любовь по-нашему).

Стереотипность употребления приводит в действие закон экономии языковых средств. Не меняя своего значения, дискурсивная конструкция теряет значимые компоненты: было и такому случиться, дрейфуя в сторону вводных оборотов: $и$ надо же было такому случиться $\rightarrow$ и надо же такому случиться $\rightarrow$ и надо же. Ср.: 
И надо же было такому случиться, что, когда он нажимал на кнопку звонка, появилась Нина Софьина. (А. Слаповский. Любовь по-нашему).

И надо же такому случиться - за несколько мгновений до того Лена хладнокровно пригнула голову, как если бы знала наперед о грозящей опасности. (Д. Емец. Таня Гроттер и колодец Посейдона).

И надо жее - плохое настроение само собой куда-то улетучилось! (Т. Рик. Лекарство от плохого настроения).

В диалогических контекстах конструкция И надо же претерпевает окончательную трансформацию. Она используется в качестве самостоятельной ответной реплики, вторичного междометия, выражающего оценку воспринятого как неожиданного, вызывающего сильное удивление, чаще связанную с положительными коннотациями, которые могут определять предпочтение данного междометия его близкому синониму Вот ведь как.

Конструкция «обрастает экспрессивными частицами и возможностью инверсии компонентов, в результате чего получается набор синонимичных вариантов:

Надо же!; Ну надо же!; Это надо же!; Это ж(е) надо!.

- Это стоматолог из поликлиники, - прошептала я ему. - Они со Струминым вместе учились. - Ну надо же, как тесен мир! - поразился Лешка. (Е. Топильская. Помни о смерти (memento тогі).

- Они зеленье? - насторожилась Ольга. Я кивнула. - Надо жсе! - восхитилась она. - А пару секунд назад были терракотовые. (Д. Донцова. Доллары изаря Гороха);

Тетка Наталья, накинув ей под утро на плечи платок, отошла на два шага в сторону, оценила свою работу и даже как будто слегка всплакнула. - Ну, надо жее, Нюра... Какая красавица... (А. Геласимов. Степные боги).

Два рассмотренных междометия: Вот ведь как и Надо же относятся к группе удивления и в принципе могут быть взаимозаменяемы. Однако «коннотативный шлейф» позволяет несколько развести эти единицы для рекомендации по их использованию в речи. Если для первой из них более характерны контексты негативного характера, то для второй - положительные. Жестово-мимическое сопровождение Надо же несколько отличается от эмоции удивления, передаваемой через Bom ведь как. Произнося Надо же! говорящий может чуть приподнять голову, широко раскрыть глаза, улыбнуться. При жестово-мимическом сопровождении междометия Bom ведь как улыбка не представляется возможной.

\section{Литература}

Балли Ш. Французская стилистика. М., 2011.

Бутовская М. Л. Язык тела: природа и культура. М., 2004. 
Иорданская Л.Н. Попытка лексикографического толкования группы русских слов со значением чувства // Машинный перевод и прикладная лингвистика. Вып. 13. М., 1970. С. 3-26.

ССРЯ 1997 - Словарь структурных слов русского языка. Под. ред. В.В. Морковкина. 1997.

Шаронов И.А. О скрытых признаках производных междометий // Скрытые смыслы в языке и коммуникации. М., 2008. С. 223-237.

Шаронов И.А. Коммуникативы и методы их описания// Материалы международной конференции Диалог 2009, вып. 8 (15). М., 2009. С. 543-548

Cruz M.P. Applications of Relevance Theory: From Discourse to Morphemes. Newcastle upon Tyne: Cambridge Scholars Publishing, 2017. P. 299-326.

Gehweiler E. From proper name to primary interjection. The case of gee! // Journal of Historical Pragmatics 9, no. 1, 2008. P. 71-93.

Lehmann C. Theory and method in grammaticalization / Zeitschrift für germanistische Linguistik, 32 (22), 2004. P. 152-187.

Traugott E.C. Subjectification in grammaticalisation // Subjectivitiy and subjectivisation. Cambridge: Cambridge University Press, 1995.

\author{
Igor A. Sharonov \\ Russian State University for the Humanities (RSUH) \\ (Moscow, Russia) \\ igor_sharonov@mail.ru
}

\title{
VOT VED' AND NADO ZHE! THE TRANSITION PATH FROM SYNTACTIC CONSTRUCTION TO SECONDARY INTERJECTION
}

The object of the article is the elucidation of the origins of secondary interjections. These interjections presumably originate from standard syntactic constructions that have been subjected in discourse to the elliptization of a number of components that convey a specific communicative situation. The transition of syntactic constructions to secondary interjections occurs in two stages. In the first stage, constructions are reconstructed for the purposes of more generalized description and begin to be used in discourse as metatextual units to prepare the interlocutor for the perception of unusual information. Stereotypical use in this position leads the construction to lose several components and to these being idiomiatized, that is, they turn into communicative formulas. These formulas serve to introduce unusual information and convey the attitude of the speaker to the same. At the second stage, communicative formulas are used in dialogue as a reaction of the interlocutor to the received information. In this position, the construction loses some further components and serves only to express the surprise of the subject at the perceived information - that is, it is transformed from a communicative formula into a secondary interjection. 
Keywords: grammaticalization, discourse, dialogue, metatext, ellipsis, desemantization, secondary intejections.

\section{References}

Balli Sh. Francuzskaya stilistika [French Stylistics]. Moscow, 2011. (In Russ.).

Butovskaya M. L. Yazyk tela: priroda i kul'tura [Body Language. Nature and Culture]. Moscow, 2004. (In Russ.).

Cruz M.P. Applications of Relevance Theory: From Discourse to Morphemes. Newcastle upon Tyne: Cambridge Scholars Publishing, 2017, p. 299-326.

Gehweiler E. From proper name to primary interjection. The case of gee! Journal of Historical Pragmatics 9, no. 1, 2008, p. 71-93.

Iordanskaya L. N. Popytka leksikograficheskogo tolkovaniya gruppy russkih slov so znacheniem chuvstva [The attempt of Russian emotion words group lexicographic description]. Mashinnyj perevod i prikladnaya lingvistika, vyp. 13, Moscow, 1970, pp. 3-26. (In Russ.).

Lehmann $\mathrm{C}$. Theory and method in grammaticalization. Zeitschrift für germanistische Linguistik, no. 32 (22), 2004, p. 152-187.

Slovar' strukturnyh slov russkogo yazyka. [Russian language dictionary of structural words] V. V. Morkovkin (ed). Moscow. 1997. (In Russ.).

Sharonov I. A. O skrytyh priznakah proizvodnyh mezhdometiy [About hidden characteristics of secondary interjections]. Skrytye smysly v yazyke i kommunikacii. Moscow, 2008, pp. 223-237. (In Russ.).

Sharonov I. A. Kommunikativy i metody ih opisaniya. Materialy mezhdunarodnoj konferencii Dialog 2009, vyp. 8 (15). Moscow, 2009, pp. 543-548. (In Russ.).

Traugott E. C. Subjectification in grammaticalisation. Subjectivitiy and subjectivisation. Cambridge, Cambridge University Press, 1995. 